\title{
Conception Rate Using the Select-Synch Protocol in Combination with a Lower Dose Progesterone-Releasing Intravaginal Insert (1.38 g) in Swiss Dairy Cows
}

\author{
F. Beuchat ${ }^{1}$, P. Berthold ${ }^{1}$, L. Gerber ${ }^{1}$, R. M. Bruckmaier ${ }^{2}$, A. Steiner ${ }^{3}$, \\ J. Hüsler ${ }^{4}$, Gaby Hirsbrunner ${ }^{3 *}$ \\ ${ }^{1}$ Clinique Vétérinaire du Vieux Château, Delémont, Switzerland \\ ${ }^{2}$ Veterinary Physiology, Vetsuisse Faculty, University of Berne, Berne, Switzerland \\ ${ }^{3}$ Clinic for Ruminants, Vetsuisse Faculty, University of Berne, Berne, Switzerland \\ ${ }^{4}$ Institute of Mathematical Statistics and Actuarial Science, University of Berne, Berne, Switzerland \\ Email: "gaby.hirsbrunner@vetsuisse.unibe.ch
}

Received October 31, 2012; revised November 27, 2012; accepted December 8, 2012

\begin{abstract}
Background: Synchronization programs have become standard in the dairy industry. In Switzerland, these programs are used but newly. The objective of this study was A) to estimate the pregnancy rate after a Select-Synch protocol including a low dosage of progesterone in CIDR $(1.38 \mathrm{~g})$. As a second step B) this pregnancy rate should be compared to cows from another Swiss study that used a Select-Synch protocol with the $1.9 \mathrm{~g}$ insert (Rudolph et al., 2011). Methods: A) 196 cows were included in the study. Cows received a CIDR $1.38 \mathrm{~g}$ and $2.5 \mathrm{ml}$ of buserelin i.m. on $\mathrm{d} 0$. On d 7, the CIDR insert was removed and $5 \mathrm{ml}$ of dinoprost was administered i.m. On d 0 a milk sample for progesterone analysis was taken. Pregnancy was determined at or more than 35 days after artificial insemination. B) The $1.38 \mathrm{~g}$ group and the $1.9 \mathrm{~g}$ group were compared as to cow and farm factors, number of preceding AI's, gynecological and uterine pretreatment and treatment itself. A forward selection procedure was used (test result considered significant if $p$-value $<0.05$ ). Results: A) The pregnancy rate, using the Select-Synch protocol with the CIDR $1.38 \mathrm{~g}$ was $44.4 \%$. B) The CIDR $1.9 \mathrm{~g}$ Select-Synch group revealed a pregnancy rate of 50.4\% (Rudolph et al., 2011). Significant differences between the groups were not found. Conclusion: The $1.38 \mathrm{~g}$ CIDR-Select-Synch protocol may be recommended for multiparous dairy cows. The pregnancy rate compared to the $1.9 \mathrm{~g}$ CIDR-Select-Synch protocol was $8 \%$ lower, but this difference was not significant.
\end{abstract}

Keywords: Cattle; Synchronization; CIDR; 1.38 g; Dairy; Swiss

\section{Introduction}

The economic pressure due to the reduction of milk price leads producers to extend the size of their farms and to increase the number of cows or to find a sideline job. These measures tend to reduce the time reserved for herd management with potentially negative consequences on observing estrus, timing of insemination and finally on fertility parameters themselves.

Although Swiss veterinarians have used hormonal treatment protocols for anestrus cows or cows with cystic ovarian disease (COD) [1], the demand for synchronization protocols such as the Ovsynch protocol [2,3] or its derivate [4] has grown in Swiss agriculture but newly. High costs and the decreasing acceptance of hormonal treatments of cattle by consumers remained the most limiting factors for expanding their use until today.

\footnotetext{
"Corresponding author.
}

The benefit of synchronization by using controlled internal drug release (CIDR) containing progesterone has been shown in many studies: Chebel et al. [5] demonstrated that the use of a CIDR insert for 7 days during a timed artificial insemination (TAI) protocol increased the proportion of functional corpus luteum (CL) in anestrus cows after AI and pregnancy per artificial insemination (P/AI) compared to protocols without CIDR [5]. Lamb et al. described a better pregnancy rate in a Cosynch-CIDR protocol compared to Cosynch alone, but only in acyclic cows or cows with a low progesterone level when PGF2alpha was administered [6]. Stevenson et al. [4] confirmed the benefit of a CIDR insert during the Ovsynch protocol to increase fertility in lactating cows having low serum progesterone before PGF2alpha injection. Rudolph and coworkers [7] recently demonstrated a pregnancy rate of $50.4 \%$ after the use of the Select-Synch protocol in Swiss dairy farms. 
The pharmaceutical industry headed for minimizing the dosage of progesterone in the CIDR insert in regard to Veterinary Public Health as negative impacts of hormone residues to environment are known [8]. However, there are but few articles describing the dose-effect relationship of progesterone supplementation in cattle [9]. The use of 2 CIDR inserts at the same time did not provoke better P/AI results than did 1 CIDR insert (1.38) in a TAI protocol. The increase of the plasma progesterone level was only $0.9 \mathrm{ng} / \mathrm{ml}$ per CIDR [10]. One time reused CIDR inserts in goats yielded acceptable pregnancy rates compared with new devices, whereas pregnancy rates were lower after twice used CIDR's [11]. Colazo and coworkers [9] could not find significant differences in the pregnancy rates of beef heifers after fixed TAI following new or used CIDR devices, although there tended to be fewer pregnancies in the group with the used CIDR's. In the United States and in parts of Europe the $1.38 \mathrm{~g}$ CIDR is used, whereas in Canada and Switzerland the $1.9 \mathrm{~g}$ CIDR is on the market.

The aims of our study were:

1) To estimate the pregnancy rate after a Select-Synch protocol using the low dosage of progesterone in CIDR (1.38 g).

2) As a second step this pregnancy rate should be compared to cows from another Swiss study that used the same Select-Synch protocol but with the $1.9 \mathrm{~g}$ insert [7].

\section{Materials and Methods}

\subsection{Study A) Animals and Inclusion Criteria}

The study was conducted from April 2010 to June 2011 in 59 dairy farms in the region of Delémont, Switzerland. Multiparous dairy cows $(n=214)$ more than 42 DIM (days in milk) of the breeds Holstein Friesian, Red Holstein, Brown Swiss and their crossbreds were included. The veterinarians performed a gynecological examination and cows diagnosed with anestrus, repeat breeders or cows diagnosed as not pregnant after a pregnancy check were included, if the uterus and uterine discharge appeared normal. Exclusion criteria were caesarian section, uterine prolapse, uterine torsion or dystocia at preceding delivery. Heifers, cows in first lactation and cows from farms using natural mating were not enrolled in the study. Cows showing lameness or any other systemic illness within 14 days prior to CIDR insertion and until the day of artificial insemination and cows not inseminated within 120 hours after CIDR removal were also excluded retrospectively.

\subsection{Study A) Treatment and Insemination}

Cows were assigned to a CIDR 1.38-Select-Synch protocol. On the first day of examination by the veterinarian (Day 0), cows received a CIDR insert (EAZI-BEED
CIDR $1380^{\circledR}$ Cattle insert, 1.38 g progesterone; Pfizer Animal Health, Zurich, Switzerland) and $2.5 \mathrm{ml}$ of buserelin i.m. $\left(\right.$ Receptal $^{\circledR} 4 \mu \mathrm{g} / \mathrm{ml}$, Veterinaria AG, Zurich, Switzerland). On day 7, the CIDR insert was removed and $5 \mathrm{ml}$ of dinoprost i.m. $\left(\mathrm{PGF}_{2 \alpha}\right.$; Dinolytic ${ }^{\circledR}, 5$ $\mathrm{mg} / \mathrm{ml}$, Pfizer Animal Health, Zurich, Switzerland) was administered. The cows were observed for estrus and inseminated respecting the AM-PM rule (cows detected in estrus AM were artificially inseminated PM and vice versa). Cows not observed in estrus within 96 hours after CIDR removal, were reexamined by a veterinarian to exclude silent heat. If clear vaginal discharge, edema of the cervix and/or increased uterine tone was detected during this examination, the cows were also inseminated.

\subsection{Study A) Milk Progesterone Test}

A milk sample was taken from each cow on d 0 of treatment. Five $\mathrm{ml}$ were collected in a plastic tube containing $30 \mathrm{mg}$ of sodium azide (Sigma-Aldrich, Bern, Switzerland) and was frozen until further analysis. Before analysis, the samples were centrifuged for $15 \mathrm{~min}$ at $1700 \times \mathrm{g}$ and the fat layer was removed. This step was repeated, and skimmed milk samples were further tested. The progesterone concentrations were determined by enzyme immunoassay as described by Meyer et al. [12]. The sensitivity of the test was $0.1 \mathrm{ng} / \mathrm{ml}$. Intra- and inter-assay coefficients of variation were 8 and $12 \%$, respectively. Cows with a progesterone level $>1 \mathrm{ng} / \mathrm{ml}$ were considered to have luteal activity. A progesterone level $<0.5$ $\mathrm{ng} / \mathrm{ml}$ was considered to represent no luteal activity and the values in between belonged to group 3 with indistinct luteal activity.

\subsection{Study A) Pregnancy Determination and Definition of Conception Rate}

Pregnancy diagnosis was determined by rectal palpation and/or transrectal ultrasound between 35 and 45 days after AI. Conception rate was determined by calculating the number of cows diagnosed as pregnant following the AI (after the protocol) divided by the total number of cows inseminated.

\subsection{Study B) Control Group}

262 cows from another Swiss study (CIDR 1.9-SelectSynch; [8]) were used as a control group. Including and excluding criteria were identical. Treatment was identical except for the higher dosage in the CIDR (1.9 $\mathrm{g}$ instead of $1.38 \mathrm{~g}$ ) and insemination management as well pregnancy determination was identical.

\subsection{Statistical Analysis}

Data were analyzed with a statistical software program (SAS Version 9.12). 
In study A the primary end point was "pregnancy after treatment".

In study $\mathrm{B}$, the $1.38 \mathrm{~g}$ group was compared to a $1.9 \mathrm{~g}$ Swiss study group that used the CIDR-Select-Synch [7]. $1.38 \mathrm{~g}$ group and $1.9 \mathrm{~g}$ group were first compared as to age of cows, DIM, number of preceding AI's, number of cows per farm and yearly milk yield per cow using chi square tests or Fisher's exact tests. Then a multiple logistic model was used to relate the success to all of the available factors; in particular treatment (CIDR $1.38 \mathrm{~g} / \mathrm{CIDR}$ $1.9 \mathrm{~g})$, age of cows $(<3.5 \mathrm{yrs} /$ between 3.5 to $5.5 \mathrm{yrs} />5.5$ yrs), DIM ( $>100 \mathrm{~d} ; \leq 100 \mathrm{~d})$ previous treatment of the uterus (yes/no), previous gynecological treatment (yes/ no), milk progesterone value $(<0.5 /$ between 0.5 to $1 />1$ $\mathrm{ng} / \mathrm{ml}$ ), and insemination (farmer's observation/checked by veterinarian). We used a forward selection procedure. A test result was considered significant if the resulting $\mathrm{p}$ value was $<0.05$.

\section{Results}

\subsection{Study A}

From a total of 214 cows, 196 cows were included in the study. 18 cows were retrospectively excluded from the study due to preceding caesarian section (1), abortion (1), dystocia (4), estrous later than 120 hours after CIDR removal (4), loss of CIDR (1), missing protocol (5), slaughter because of udder problems (2). Pregnancy rate using the Select-Synch protocol with the CIDR $1.38 \mathrm{~g}$ was $44.4 \%$ (c.i. $36.0 \%, 52.9 \%$ ).

\subsection{Study B}

In Table 1, the descriptive measures of both groups for the cows and farms are listed as age, uterine and gynecological pretreatments, previous AI's, insemination, progesterone value, and farmers business. In Table 2 median (25\%/75\% quartiles) of the metric data age of cows, DIM, number of AI's, number of cows per farm and yearly milk yield of cows are described for both groups and compared with the Mann-Whitney test. Using the multiple logistic regression model with the forward selection method, none of the factors age of cows, DIM, uterine and gynecological pretreatment, number of previous AI's, success of treatment (conception rate) and farmer's business exceeded the significant level. Significant differences between the groups CIDR-Select Synch $1.9 \mathrm{~g}$ and CIDR-Select Synch $1.38 \mathrm{~g}$ were only found for the parameters number of cows per farm, yearly milk yield per cow and progesterone value (Tables 1 and 2). The overall pregnancy rate of the CIDR-Select-Synch 1.9 g group was $50.4 \%$ (95\% c.i. $46.4 \%, 59.1 \%)$. The difference of the overall pregnancy rates of the two groups was $8 \%(95 \%$ c.i. $17.3 \%,-1.8 \%)$ in favor of the CIDR-Select Synch $1.9 \mathrm{~g}$ group. This difference was not significant.
Table 1. Study A: Percentage of cows in relation to age, previous uterine and gynecological treatment, previous AI, insemination, milk progesterone value, and farmers business in the $1.38 \mathrm{~g}$ CIDR Select-Synch and in the $1.9 \mathrm{~g}$ group.

\begin{tabular}{|c|c|c|c|}
\hline Parameters & $\begin{array}{l}\text { CIDR } 1.38 \\
\text { Select-Synch }\end{array}$ & $\begin{array}{c}\text { CIDR } 1.9 \\
\text { Select-Synch }\end{array}$ & $\mathrm{p}$-Value \\
\hline \multicolumn{4}{|l|}{ Age } \\
\hline$<3.5$ years & $14.80 \%$ & $13.60 \%$ & 0.176 \\
\hline $3.5-5.5$ years & $34.50 \%$ & $44 \%$ & \\
\hline$>5.5$ years & $50.70 \%$ & $42.40 \%$ & \\
\hline \multicolumn{4}{|l|}{$\begin{array}{c}\text { Uterine } \\
\text { pretreatment }\end{array}$} \\
\hline Yes & $7.80 \%$ & $13.40 \%$ & 0.08 \\
\hline No & $92.20 \%$ & $86.60 \%$ & \\
\hline \multicolumn{4}{|l|}{$\begin{array}{l}\text { Gynecological } \\
\text { pretreatment }\end{array}$} \\
\hline Yes & $16.20 \%$ & $10.30 \%$ & 0.124 \\
\hline No & $83.80 \%$ & $89.70 \%$ & \\
\hline \multicolumn{4}{|l|}{ Previous AI } \\
\hline Yes & $31.70 \%$ & $35.90 \%$ & 0.4 \\
\hline No & $68.30 \%$ & $64.10 \%$ & \\
\hline \multicolumn{4}{|l|}{ Insemination } \\
\hline Blind & $87.30 \%$ & $78.70 \%$ & 0.034 \\
\hline Checked & $12.70 \%$ & $21.30 \%$ & \\
\hline \multicolumn{4}{|l|}{ Progesterone } \\
\hline$<0.5 \mathrm{ng} / \mathrm{ml}$ & $19 \%$ & $44.40 \%$ & $<0.0001$ \\
\hline $0.5-1 \mathrm{ng} / \mathrm{ml}$ & $28.20 \%$ & $14.40 \%$ & \\
\hline$>1 \mathrm{ng} / \mathrm{ml}$ & $52.80 \%$ & $41.20 \%$ & \\
\hline \multicolumn{4}{|l|}{ Farmer's business } \\
\hline Main & $97.90 \%$ & $95.50 \%$ & 0.23 \\
\hline Side & $2.10 \%$ & $4.50 \%$ & \\
\hline
\end{tabular}

Table 2. Study B: Median values (25\%/75\%) and p-values of the groups CIDR Select-Synch $1.38 \mathrm{~g}$ versus $1.9 \mathrm{~g}$. Number of cows per farm and yearly milk yield per farm were significantly different.

\begin{tabular}{cccc}
\hline Parameters & $\begin{array}{c}\text { CIDR 1.38 } \\
\text { Select-Synch }\end{array}$ & $\begin{array}{c}\text { CIDR 1.9 } \\
\text { Select-Synch }\end{array}$ & p-Value \\
\hline $\begin{array}{c}\text { Age of cows } \\
\text { (years) }\end{array}$ & $5.5(4 / 7)$ & $5(4 / 6.5)$ & 0.6967 \\
DIM & $89(68 / 131)$ & $97.5(71 / 142.5)$ & 0.1415 \\
$\begin{array}{c}\text { Number of } \\
\text { AI's }\end{array}$ & $0(0 / 1)$ & $0(0 / 1)$ & 0.5973 \\
$\begin{array}{c}\text { Number of } \\
\text { cows/farm }\end{array}$ & $30(23 / 40)$ & $24(18 / 32)$ & $<0.0001$ \\
$\begin{array}{c}\text { Yearly milk } \\
\text { yield/cow (kg) }\end{array}$ & $8000(7500 / 9000)$ & $7500(6800 / 8150)$ & $<0.0001$ \\
\hline
\end{tabular}

\section{Discussion}

"Classic" synchronization protocols [13] and protocols including a CIDR [4,14-17] have been used in dairy 
herds to manage reproduction more efficiently. The benefit of the administration of 2 CIDR's was obvious in anovular cows, where cyclicity was more likely to be resumed [18-20]. CIDR treatment provided priming with progesterone that reduced the incidence of short luteal phases after AI [18,21].

The pregnancy rate for the $1.38 \mathrm{~g}$ CIDR Select-Synch was $44 \%$. The control group (CIDR $1.9 \mathrm{~g}$ Select-Synch) revealed a pregnancy rate of $50.4 \%$ [7], which was not significantly higher than that of the $1.38 \mathrm{~g}$ group. Both pregnancy rates were comparable to another Swiss study from 2011 that revealed a first insemination pregnancy rate of $45.1 \%$ and an overall pregnancy rate of $45.3 \%$ in regularly controlled Swiss dairies [22]. Differences between the $1.38 \mathrm{~g}$ group and the control group were a higher number of cows per farm (mean: 30 versus 24) and an increased milk yield (mean 8000 versus 7500 liters per year) in the $1.38 \mathrm{~g}$ group. In Switzerland, there are no data available that pregnancy rate is dependent on number of cows per farm or milk production. There is only one study comparing organically and conventionally producing Swiss farms where fertility parameters were not significantly different [23]. Additionally, the progesterone values at the beginning of the protocol were different between the groups: In the $1.38 \mathrm{~g}$ group, $52.8 \%$ of the cows started with $>1 \mathrm{ng} / \mathrm{ml}$ progesterone as compared to $41.2 \%$ in the control group. Data of Bisinotto et al. [24] indicate that follicular wave of the ovulatory follicle and not cyclic status had the greatest effect reducing P/AI of dairy cows. In another study using a synchronization protocol including a CIDR, no significant difference was found for P/AI between cows with progesterone $\geq 1$ as compared to $<1[5]$.

Our encouraging results lead to the conclusions that the dosage of progesterone in CIDR inserts can be reduced from $1.9 \mathrm{~g}$ to $1.38 \mathrm{~g}$ without significantly affecting pregnancy rates. Additionally, pregnancy rates following the $1.38 \mathrm{~g}$ Select-Synch in anestrus cows, repeat breeders or cows diagnosed as not pregnant after a pregnancy check was comparable to the pregnancy rate in regularly controlled Swiss dairies [22].

\section{Acknowledgements}

The authors thank Pfizer Animal Health, Zurich, Switzerland and MSD (Veterinaria AG), Zurich, Switzerland for providing pharmaceuticals and financial support for this study. The authors also extend their gratitude to the participating veterinarians, and the dairy producers.

\section{REFERENCES}

[1] A. Busato, C. Minder and U. Küpfer, "Importance and Seasonal Pattern of Fertility Disorders in 80 Swiss Dairy Farms," Epidemiol Sante Anim, Vol. 31-32, No. 1, 1997, p. 5.

[2] J. R. Pursley, M. O. Mee and M. C. Wiltbank, "Synchronization of Ovulation in Dairy Cows Using PGF2alpha and GnRH," Theriogenology, Vol. 44, No. 7, 1995, pp. 915-923. doi:10.1016/0093-691X(95)00279-H

[3] J. R. Pursley, R. W. Silcox and M. C. Wiltbank, "Effect of Time of Artificial Insemination on Pregnancy Rates, Calving Rates, Pregnancy Loss, and Gender Ratio after Synchronization of Ovulation in Lactating Dairy Cows," Journal of Dairy Science, Vol. 81, No. 8, 1998, pp. 21392144. doi:10.3168/jds.S0022-0302(98)75790-X

[4] J. S. Stevenson, J. R. Pursley, H. A. Garverick, P. M. Fricke, D. J. Kesler, J. S. Ottobre and M. C. Wiltbank, "Treatment of Cycling and Noncycling Lactating Dairy Cows with Progesterone during Ovsynch," Journal of Dairy Science, Vol. 89, No. 7, 2006, pp. 2567-2578. doi:10.3168/jds.S0022-0302(06)72333-5

[5] R. C. Chebel, M. J. Al-Hassan, P. M. Fricke, J. E. Santos, J. R. Lima, C. A. Martel, J. S. Stevenson, R. Garcia and R. L. Ax, "Supplementation of Progesterone via Controlled Internal Drug Release Inserts during Ovulation Synchronization Protocols in Lactating Dairy Cows," Journal of Dairy Science, Vol. 93, No. 3, 2010, pp. 922-931. doi:10.3168/jds.2009-2301

[6] G. C. Lamb, J. S. Stevenson, D. J. Kesler, H. A. Garverick, D. R. Brown and B. E. Salfen, "Inclusion of an Intravaginal Progesterone Insert Plus GnRH and Prostaglandin F2alpha for Ovulation Control in Postpartum Suckled Beef Cows," Journal of Animal Science, Vol. 79, No. 9, 2001, pp. 2253-2259.

[7] J. Rudolph, R. M. Bruckmaier, R. Kasimanickam, A. Steiner, M. Kirchhofer, J. Huesler and G. Hirsbrunner, "Comparison of the Effect of a CIDR-Select Synch versus a Long-Term CIDR Based AI Protocol on Reproductive Performance in Multiparous Dairy Cows in Swiss Dairy Farms," Reproductive Biology and Endocrinology, Vol. 9, 2011, p 151. doi:10.1186/1477-7827-9-151

[8] J. Raloff, "Hormones: Here's the Beef: Environmental Concerns Reemerge over Steroids Given to Livestock," Science News, Vol. 161, No. 1, 2002, pp. 10-12. doi: $10.2307 / 4013043$

[9] M. G. Colazo, J. P. Kastelic, P. R. Whittaker, Q. A. Gavaga, R. Wilde and R. J. Mapletoft, "Fertility in Beef Cattle Given a New or Previously Used CIDR Insert and Estradiol, with or without Progesterone," Animal Reproduction Science, Vol. 81, No. 1-2, 2004, pp. 25-34. doi:10.1016/j.anireprosci.2003.09.003

[10] J. R. Lima, F. A. Rivera, C. D. Narciso, R. Oliveira, R. C. Chebel and J. E. Santos, "Effect of Increasing Amounts of Supplemental Progesterone in a Timed Artificial Insemination Protocol on Fertility of Lactating Dairy Cows," Journal of Dairy Science, Vol. 92, No. 11, 2009, pp. 54365446. doi:10.3168/jds.2009-2134

[11] M. Vilarino, E. Rubianes and A. Menchaca, "Re-Use of Intravaginal Progesterone Devices Associated with the Short-Term Protocol for Timed Artificial Insemination in Goats," Theriogenology, Vol. 75, No. 7, 2011, pp. 1195 1200. doi:10.1016/j.theriogenology.2010.11.030

[12] H. H. D. Meyer, B. Güven and H. Karg, "Enzymimmun- 
test (EIA) auf Mikrotiterplatten zur Progesteronbestimmung in Magermilchproben," Wien Tierärztl Mschr, Vol. 73, 1986, pp. 86-94.

[13] J. R. Pursley, M. R. Kosorok and M. C. Wiltbank, "Reproductive Management of Lactating Dairy Cows Using Synchronization of Ovulation," Journal of Dairy Science, Vol. 80, No. 2, 1997, pp. 301-306. doi:10.3168/jds.S0022-0302(97)75938-1

[14] J. A. Bartolome, J. J. van Leeuwen, M. Thieme, O. G. Safilho, P. Melendez, L. F. Archbald and W. W. Thatcher, "Synchronization and Resynchronization of Inseminations in Lactating Dairy Cows with the CIDR Insert and the Ovsynch Protocol," Theriogenology, Vol. 72, No. 6, 2009, pp. 869-878. doi:10.1016/j.theriogenology.2009.06.008

[15] S. T. Dewey, L. G. Mendonca, G. Lopes Jr., F. A. Rivera, F. Guagnini, F., R. C. Chebel and T. R. Bilby, "Resynchronization Strategies to Improve Fertility in Lactating Dairy Cows Utilizing a Presynchronization Injection of GnRH or Supplemental Progesterone: I. Pregnancy Rates and Ovarian Responses," Journal of Dairy Science, Vol. 93, No. 9, 2010, pp. 4086-4095. doi:10.3168/jds.2010-3233

[16] S. Z. El-Zarkouny, J. A. Cartmill, B. A. Hensley and J. S. Stevenson, "Pregnancy in Dairy Cows after Synchronized Ovulation Regimens with or without Presynchronization and Progesterone," Journal of Dairy Science, Vol. 87, No. 4, 2004, pp. 1024-1037.

[17] P. Melendez, G. Gonzalez, E. Aguilar, O. Loera, C. Risco and L. F. Archbald, "Comparison of Two Estrus-Synchronization Protocols and Timed Artificial Insemination in Dairy Cattle," Journal of Dairy Science, Vol. 89, No. 12, 2006, pp. 4567-4572. doi:10.3168/jds.S0022-0302(06)72506-1

[18] R. L. Cerri, H. M. Rutigliano, R. G. Bruno and J. E. San- tos, "Progesterone Concentration, Follicular Development and Induction of Cyclicity in Dairy Cows Receiving Intravaginal Progesterone Inserts," Animal Reproduction Science, Vol. 110, No. 1-2, 2009, pp. 56-70. doi:10.1016/j.anireprosci.2007.12.005

[19] R. C. Chebel, J. E. Santos, R. L. Cerri, H. M. Rutigliano and R. G. Bruno, "Reproduction in Dairy Cows Following Progesterone Insert Presynchronization and Resynchronization Protocols," Journal of Dairy Science, Vol. 89 , No. 11, 2006, pp. 4205-4219. doi:10.3168/jds.S0022-0302(06)72466-3

[20] A. Gumen and M. C. Wiltbank, "Length of Progesterone Exposure Needed to Resolve Large Follicle Anovular Condition in Dairy Cows," Theriogenology, Vol. 63, No. 1, 2005, pp. 202-218. doi:10.1016/j.theriogenology.2004.04.009

[21] F. M. Rhodes, S. McDougall, C. R. Burke, G. A. Verkerk and K. L. Macmillan, "Invited Review: Treatment of Cows with an Extended Postpartum Anestrous Interval," Journal of Dairy Science, Vol. 86, No. 6, 2003, pp. 1876-1894. doi:10.3168/jds.S0022-0302(03)73775-8

[22] D. Feyer, D. Kemper, M. Reist and T. Kaufmann, "Bluetongue Disease: Impact of the 2008 Vaccination on Fertility in Supervised Dairy Herds," Schweizer Archiv für Tierheilkunde, Vol. 153, No 6, 2011, pp. 257-262.

[23] M. Roesch, M. G. Doherr and J. W. Blum, "Performance of Dairy Cows on Swiss Farms with Organic and Integrated Production," Journal of Dairy Science, Vol. 88, No. 7, 2005, pp. 2462-2475. doi:10.3168/jds.S0022-0302(05)72924-6

[24] R. S. Bisinotto, R. C. Chebel and J. E. Santos, "Follicular Wave of the Ovulatory Follicle and Not Cyclic Status Influences Fertility of Dairy Cows," Journal of Dairy Science, Vol. 93, No. 8, 2010, pp. 3578-3587. doi:10.3168/jds.2010-3047 